\title{
Inspiring excellence in musculoskeletal sports medicine
}

\author{
Nikolaos Malliaropoulos, ${ }^{1,2}$ Mourad Ghrairi, ${ }^{3}$ Moustafa Al Hashimi, ${ }^{4}$ \\ Yacine Zerguini, ${ }^{5}$ Nat Padhiar ${ }^{1,2}$
}

\begin{abstract}
Musculoskeletal sports medicine is one of the main components of sport and exercise medicine (SEM), and injury prevention is a challenge for everyone involved in sport - sports physicians, athletes, coaches, clubs and all the other support staff. In this issue, we have brought together the latest research in injury prevention and musculoskeletal SEM.
\end{abstract}

\section{DELAYING ACL RECONSTRUCTION OR TREATING THE INJURY WITH EXERCISE THERAPY ALONE MAY ALTER THE FINAL PROGNOSIS}

ACL injuries are still a major challenge in everyday clinical practice. Evidence-based recommendations for surgical intervention, as opposed to conservative management, has not been clearly established yet. This study (see page 1622) provides the basis for clinicians to offer individualised management options, conservative or surgical, tailored to the patient's needs and the characteristics of the injury.

\section{DECONSTRUCTING A POPULAR MYTH: WHY KNEE ARTHROSCOPY IS NO BETTER THAN PLACEBO SURGERY FOR DEGENERATIVE MENISCAL TEARS}

It is traditionally suggested that meniscal tears cause pain and that this can be relieved by removing the damaged tissue. In this

${ }^{1}$ Centre Sports and Exercise Medicine, Queen Mary University of London, London, UK

${ }^{2}$ European SportsCare, Harley Street, London W1 G 7HE, UK

${ }^{3}$ FIFA Medical Centre of Excellence, Dubai \& UAE Football Association, Dubai, United Arab Emirates

${ }^{4}$ UAE Football Association Dubai, United Arab Emirates ${ }^{5}$ Médecine et Traumatologie du Sport, Clinique Chahrazed, Cheraga, Alger, Algeria

Correspondence to Dr Nikolaos Malliaropoulos; contact@sportsmed.gr review (see page 1630), the authors deconstruct this myth and discuss the possible placebo effects of having a knee arthroscopy. The indications for knee surgery are critically evaluated, and the concept of 'mechanical symptoms' is explored.

\section{SURGICAL CRITERIA FOR FEMOROACETABULAR IMPINGEMENT SYNDROME: A SCOPING REVIEW}

Femoroacetabular impingement (FAI) is increasingly recognised as a major cause of hip pain in athletes. Despite the increasing prevalence in sport, agreed criteria for choosing conservative or surgical management appear to be missing. In this scoping review (see page 1605), a wide range of symptoms and interventions are analysed, and suggestions are put forward regarding the criteria for surgical intervention in cases of FAI.

\section{IS REDUCED HIP RANGE OF MOTION A RISK FACTOR FOR GROIN PAIN IN ATHLETES? A SYSTEMATIC REVIEW WITH CLINICAL APPLICATIONS}

Exercise-related groin pain is very common in all sports, all levels of participation. The aetiology is multifactorial, but the relationship between pain and range of movement (ROM) has been a source of interest for some time. This review (see page 1611) outlines the possible relationship between hip pain and ROM and provides clinicians with helpful advice in assessing patients and identifying risk factors.

\section{TH CONGRESS OF ECOSEP WITH FIFA UPDATE IN DUBAI}

The FIFA Medical Centre of Excellence in Dubai, in collaboration with the European
College of Sports and Exercise Medicine Physicians (ECOSEP), welcomes the sports medicine community to the 5 th Congress, to be held 9-10 December 2017 at the Mohammed Bin Rashid University of Medicine and Health Sciences in Dubai, United Arab Emirates.

We at ECOSEP are dedicated to encouraging collaboration between SEM organisations and SEM centres on the globe. To achieve this, we have assembled outstanding speakers from around the world who will cover a wide range of exciting topics over the two days of the Congress. Attendees will hear about the latest research and take part in panel discussions, symposia and workshops to stimulate their minds and enhance their knowledge base.

At the 5th Congress of the ECOSEP and FIFA Football Medicine, East and West will come together to share their knowledge and experience in the fascinating field of SEM, and delegates will be able to experience the wonderful culture and diversity of Dubai.

Young SEM clinicians will be able to showcase their research in the form of posters, abstracts and oral presentations, and everyone will benefit from daily interacting with the experts.

The final programme can be found on the ECOSEP website http://ecosep.eu/ wp-content/uploads/2017/05/1.BrouchureFinal.pdf

We hope to meet you all there!

Competing interests None declared.

Provenance and peer review Commissioned; internally peer reviewed.

(c) Article author(s) (or their employer(s) unless otherwise stated in the text of the article) 2017. All rights reserved. No commercial use is permitted unless otherwise expressly granted.

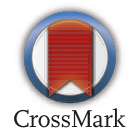

To cite Malliaropoulos N, Ghrairi M, Al Hashimi M, et al. Br J Sports Med 2017;51:1575.

Br J Sports Med 2017:51:1575 10.1136/bjsports-2017-098590 